\title{
Can Erectile Dysfunction Predict Major Cardiovascular Events?
}

\author{
Norbert A. Szekeres', Zsuzsánna Jeremiás², Árpád Olivér Vida1', Orsolya Mártha1, Daniel Porav- \\ Hodade $^{1}$
}

1 Department of Urology, University of Medicine and Pharmacy, Tîrgu Mureș, Romania

2 Department of Internal Medicine, University of Medicine and Pharmacy, Tîrgu Mureș, Romania

\section{CORRESPONDENCE}

Norbert A. Szekeres

38 Gheorghe Marinescu St

540139 Tîrgu Mureș, Romania

Tel: 0265215551

Email: szekeresnorbi@yahoo.com

\section{ARTICLE HISTORY}

Received: 2 May, 2016

Accepted: 30 May, 2016
Zsuzsánna Jeremiás • 38 Gheorghe Marinescu St, 540139 Tîrgu Mureș, Romania, Tel: +40 265215551 Email: zs.jeremias@yahoo.com

Árpád Olivér Vida • 38 Gheorghe Marinescu St, 540139 Tîrgu Mures, Romania, Tel: +40 265215551 Email: vidaarpad@yahoo.com

Orsolya Mártha • 38 Gheorghe Marinescu St, 540139 Tîrgu Mureș, Romania, Tel: +40 265215551 Email: orsim@hotmail.com

Daniel Porav-Hodade $\cdot 38$ Gheorghe Marinescu St, 540139 Tîrgu Mureș, Romania, Tel: +40 265215551 Email: dporav@yahoo.com

\begin{abstract}
It is estimated that erectile dysfunction (ED) affects more than 150 million people worldwide and this number is expected to double by the year 2025. Vascular component represents the most important etiological cause of erectile dysfunction. ED shares almost all risk factors, such as hypertension, diabetes mellitus, hyperlipidaemia and smoking, with arteriosclerosis. Moderate to severe ED is associated with a considerably increased risk for coronary heart disease (CHD). This review was conducted in May 2016, when the PubMed database was searched using the combination of the terms "erectile dysfunction" and "cardiovascular diseases", "coronary artery diseases" and "risk factors". In this review, we analyzed the published literature, regarding the predictive role of ED in CVD and the association of ED risk factors with CVD risk factors, aiming to draw particular attention on the role of sexual inquiry of all men to prevent or decrease major cardiovascular events. In conclusion, the early detection of ED can prevent major cardiovascular events with early management of cardiovascular risk and permits to include patients in a risk stratification group. Erectile function should be evaluated using questionnaires in all male patients to prevent and decrease the rates of major cardiovascular events.
\end{abstract}

Keywords: erectile dysfunction, cardiovascular diseases, coronary artery diseases, risk factors

\section{INTRODUCTION}

Erectile dysfunction (ED) is defined as the inability of the male to attain and maintain an erect penis with sufficient rigidity at a sufficient level to permit satisfactory sexual intercourse. ${ }^{1}$ The vascular component represents the most important etiological cause of erectile dysfunction. ${ }^{2} \mathrm{ED}$ has been associated with many other cardiovascular risk factors, such as hypertension, hyperlipidaemia, diabetes mellitus or smoking. ${ }^{3-7}$ Any disease located at the level of the systemic vascular bed, affects the penile arteries too, as it affects the blood supply of the genital organs. Consequently, patients with heart diseases show frequent symptoms of ED. ${ }^{8,9}$ It has been suggested that ED may represent a marker of lack of vascular integrity in general. ${ }^{10} \mathrm{ED}$ could therefore serve as a predictive symptom for potentially life-threatening coronary heart disease 
(CHD) or stroke. ${ }^{11}$ Studies have suggested that the role of $\mathrm{ED}$ as an independent risk factor for future cardiovascular events is even independent from the classical risk factors, such as diabetes and hypertension. ${ }^{12,13}$ Moderate to severe ED was associated with a considerably increased risk for CHD and stroke. ${ }^{14}$ Several studies showed that ED is associated with many CHD risk factors, including diabetes mellitus, hypertension, smoking and abnormal lipids. ${ }^{15-18}$ It has been suggested that ED may be considered as a clinical manifestation of a functional (endothelial dysfunction) or structural abnormality affecting penile circulation, as part of a more generalized vascular disorder. ${ }^{19,20}$ So far, the predictive role of $\mathrm{ED}$ as a marker of subclinical coronary artery disease (CAD) has not been completely elucidated. Pathological calcification in the coronary arteries, which is a common feature of atherosclerosis, is thought to be present even in the early subclinical phases of the atherosclerotic plaque formation..$^{21-23}$

\section{SYSTEMATIC REVIEW METHODOLOGY}

This review was conducted in May 2016, when the PubMed database was searched using the combination of the following terms: "erectile dysfunction" and "cardiovascular diseases", "coronary artery diseases" and "risk factors". Additional references were included by cross-referencing the bibliography of selected articles.

We intended to identify published articles discussing the predictive role of erectile dysfunction in the development of cardiovascular diseases and coexisting risk factors in ED and cardiovascular diseases (CVD). The PubMed database search results identified 2528 references. Articles written in other languages than English were excluded.

\section{DEFINITION AND PREVALENCE OF ERECTILE DYSFUNCTION}

After many years when the term "impotence" was used, the NIH Consensus Development Conference (1992) suggested to use the term "erectile dysfunction" instead, to denote the constant inability of the male to attain and mantain an erect penis with sufficient rigidity to permit satisfactory sexual intercourse. ${ }^{1}$ A cross-sectional study on 2126 adult males enroled in the 2001-2002 National Health and Nutrition Examination Survey indicated the presence of various degrees of erectile dysfunction in over 18 million men in the US, representing $18.4 \%$ of the male population aged 20 years or older. ${ }^{24}$

The incidence of erectile dysfunction in Romania has been estimated at $3 \%$ in young men aged between 15-25 years and at $7 \%$ in those aged between $25-45$ years, increasing up to $22 \%$ in men aged between $45-55$ years. ${ }^{25}$

It is estimated that $\mathrm{ED}$ affects 150 million people worldwide and this number is expected to more than double by the year 2025. ${ }^{26}$

\section{ETIOLOGY OF ERECTILE DYSFUNCTION}

For the correct diagnosis it is necessary to identify the cause of ED, and proper evaluation of the psychological, neurological, hormonal, and vascular system is required to identify more severe comorbidities and to treat them properly.

Vasculogenic ED. Endothelial dysfunction seems to be the link between vasculogenic ED and macrovascular disease. ${ }^{27}$ The severity of ED has been associated with the extent of angiographically confirmed CAD. ${ }^{28}$ Patients with ED present high rates of macrovascular atherosclerosis, as well as its main precursor, hyperlipidemia. ${ }^{27,28} \mathrm{~A}$ recent meta-analysis of 740 patients from 6 clinical trials in 4 countries found that treatments for cardiac risk factors (lifestyle modifications and pharmacotherapy) were associated with a significant increase in the International Index of Erectile Dysfunction (IIEF-5) score and improvements in sexual function, indicating a common pathophysiological process for ED and cardiovascular disease. ${ }^{29}$

Psychogenic ED. Psychogenic ED is the form related to stress, performance anxiety, or overt psychological disorders, such as depression or schizophrenia. ${ }^{28,30}$ Several factors such as traumatic or abusive experiences, inadequate sex education or social pressures are likely to contribute to sexual dysfunction. ${ }^{30}$

Neurogenic ED. Central nervous system disorders and spinal cord injury can impede initiation and maintenance of an erection. The degree and severity of ED is highly associated with the extent of the neurological lesions and depend also on its nature and location. ${ }^{30,31}$

Hormonal ED. Androgen deficiency is a recognized cause for decreased libido and erectile and ejaculatory function. Testosterone regulates the expression of NO synthase and phosphodiesterase-5, and maintains the integrity of vascular smooth muscle and endothelium. ${ }^{30,31}$ Low testosterone is not only associated with ED, but also with cardiovascular morbidity and mortality. Testicular disorders, such as orchitis and cryptorchidism, hypothalamic-pituitary disregulation, as found in pituitary tumors and hemochromatosis, and generalized chronic diseases are common causes of androgen deficiency. ${ }^{31}$ Hyperprolactinemia, often due to antidopaminergic pharmacotherapy, inhibits the release of $\mathrm{GnRH}$ and causes hypogonadotropic hypogonadism. ${ }^{31}$ 
Drug-induced ED. Many medications used to treat systemic illnesses can lead to ED, including antipsychotic, antidepressant, and antihypertensive drugs. Risperidone, olanzapine, and serotonin reuptake inhibitors have the highest probability of causing sexual dysfunction. Thiazides, spironolactone, and beta-blockers can also cause ED. ${ }^{30}$

Lifestyle factors and systemic disorders. Smoking contributes to ED both indirectly though its atherogenic effects and endothelial injury, and directly through the effects on cavernosal smooth muscle. While a small amount of alcohol intake improves libido and erection, larger amounts of alcohol trigger central sedation and transient $\mathrm{ED}$, and chronic alcoholism can cause hypogonadism and penile neuropathy. ${ }^{31}$ In addition, diabetes mellitus, chronic kidney, liver, and pulmonary disease, as well as a sedentary lifestyle and sleep disorders may cause ED. ${ }^{30}$

\section{COMMON RISK FACTORS IN ED AND CVD}

The prevalence of cardiovascular risk factors is significantly higher in men with erectile dysfunction at all ages, while the lack of physical activity has been identified as a powerful independent risk factor for erectile dysfunction. ${ }^{32-34}$ The crude prevalence of erectile dysfunction was over $50 \%$ among men with diabetes. ${ }^{35}$ The risk factors of ED include advanced age, hypertension, dyslipidemia, metabolic syndrome, cardiovascular disease, central neuropathologic conditions, psychological factors, diabetes mellitus (DM), radical prostatectomy and the use of certain medications prescribed for the treatment of depression and hypertension. ${ }^{36}$

Onder et al. observed a positive correlation between ED severity and coronary artery calcium (CAC) levels. A retrospective study shows that early perfusion of acute ST elevation myocardial infarction (STEMI) can preserve erectile function and percutaneus coronary intervention (PPCI) is superior to thrombolytic treatment (TT) for reducing the prevalence of ED after STEMI. ${ }^{37}$

\section{DOES ERECTILE DYSFUNCTION PRECEDE CAD?}

Montorsi et al. proposed the artery-size hypothesis, as a common pathophysiologic mechanism is the endothelial dysfunction and flow-limiting stenosis linking ED and CAD. ${ }^{38,39}$ Larger vessels tolerate better the same amount of endothelial dysfunction and/or atherosclerotic burden. A significant proportion of patients with angiographically documented CAD have ED and this condition may become evident prior to angina symptoms in almost $70 \%$ of cases. ${ }^{39}$ The Princetone III consensus panel defines cardiovascular risk in patients with ED as the risk of cardiovas- cular morbid events in a 3- to 5-year interval from the onset of ED (American College of Cardiology Foundation/ American Heart Association [ACCF/AHA class Ib]..$^{38-40}$ Erectile dysfunction commonly occurs in the presence of silent $\mathrm{CAD},{ }^{38,41-43}$ in a time period of 2 to 5 years between the onset of ED and CAD event [ACCF/AHA class Ia]. ${ }^{38,39,44,45} \mathrm{ED}$ is far more predictive of CAD in men 40 to 49 years of age than in older men, ${ }^{46}$ and the incidence of atherosclerotic cardiovascular events in younger men has been proved to be 7 times higher in the general male population in Western Australia. ${ }^{47}$ The more severe forms of ED have been associated with a significantly greater risk of major cardiovascular events, ${ }^{48} \mathrm{CAD}$, extent of CAD ${ }^{14,28,42,44}$ and risk of PAD (ACCF/AHA class Ia). ${ }^{49}$ The correct treatment of ED will not affect negatively the status of cardiovascular health. ${ }^{50}$

\section{SEXUAL ACTIVITY AND CV RISK STRATIFICATION (Princeton III Consensus recommendations) ${ }^{48}$}

\section{Low-risk Patients}

The low-risk group is represented by patients for whom sexual activity is not associated with a significant cardiovascular risk (Table 1).

TABLE 1. Princeton Guidelines

\begin{tabular}{|c|c|}
\hline \multirow[t]{7}{*}{ High risk } & unstable or refractory angina pectoris \\
\hline & uncontrolled hypertension \\
\hline & CHF (NYHA class IV) \\
\hline & recent MI without intervention (<2 weeks) \\
\hline & $\begin{array}{l}\text { high-risk arrhythmia (ventricular tachycardia, } \\
\text { implanted cardioverter defibrillator, atrial } \\
\text { fibrillation) }\end{array}$ \\
\hline & $\begin{array}{l}\text { moderate to severe valve diseases, particu- } \\
\text { larly aortic stenosis. }\end{array}$ \\
\hline & obstructive hypertrophic cardiomyopathy \\
\hline \multirow[t]{7}{*}{ Low risk } & controlled hypertension \\
\hline & mild valvular disease \\
\hline & LVD/CHF (NYHA I,II) \\
\hline & 5 MET \\
\hline & post succesfull revascularization \\
\hline & (coronary artery by pass,stenting,angioplasty) \\
\hline & without ischemia on recent exercise testing \\
\hline \multirow[t]{4}{*}{ Intermediate risk } & mild or moderate stable angina pectoris \\
\hline & past MI (2-8 wks) \\
\hline & $\mathrm{CHF}$ (NYHA class III) \\
\hline & $\begin{array}{l}\text { PAD and a history of stroke or transient isch- } \\
\text { emic attack }\end{array}$ \\
\hline
\end{tabular}




\section{Intermediate-risk Patients}

Intermediate risk patients will be classified, according to the results of paraclinical investigations, into the low-risk or high-risk class. When the patient cannot complete a standard cycloergometric test, chemical stress tests (nuclear imaging associated with dipyridamole or adenosine) are appropriate.

\section{High-risk Patients}

High-risk patients are patients in whom the cardiac condition is severe or unstable enough to be associated with a significant risk in case of sexual activity.

\section{CONCLUSION}

ED has common risk factors with CVD, however this is an independent marker of increased risk for CVD and a marker of significantly increased risk for CVD, CAD, stroke, and all-cause mortality. It is necessary to evaluate erectile function in all men with questionnaires (IIEF-15, IIEF-5) to prevent and decrease the rates of major cardiovascular events in urological, cardiological or primary care practice. The early detection of ED can prevent major cardiovascular events with early manegement of cardiovascular risk, and permits to include patients in a risk stratification group both for ED and CVD.

\section{CONFLICT OF INTEREST}

Nothing to declare.

\section{ACKNOWLEDGEMENT}

This research was supported by the Cardio Med Medical Center, project no. CAM/2015/RD/39.

\section{REFERENCES}

1. NIH Consensus Conference. Impotence. $\mathrm{NIH}$ development panel on impotence. JAMA. 1993;270(1):83-90.

2. Lue TF, ed. Impotence and infertility. In: Vaughan ED Jr, Perlmutter AP, eds. Atlas of Clinical Urology. Vol 1. Philadelphia, Pa: Current Medicine, Inc; 1999.

3. Feldman HA, Goldstein I, Hatzichristou D, Krane RJ, McKinlay JB. Impotence and its medical and psychological correlates: results of the Massachussets Male Aging study. J Urol. 1994;151:54-61.

4. Seftel AD, Sun P, Swindle R. The prevalence of hypertension, hyperlipidemia, diabetes mellitus and depression in men with erectile dysfunction. J Urol. 2004;171:2341-2345.

5. Solomon H, Man JW, Jackson G. Erectile dysfunction and the cardiovascular patient: endothelial dysfunction is the common denominator. Heart. 2003;89:251-253.

6. Feldman HA, Johannes CB, Derby CA, et al. Erectile dysfunction and coronary risk factors: prospective results from the Massachusetts male aging study. Prev Med. 2000;30:328-338.
7. Fung MM, Bettencourt R, Barrett-Connor E. Heart disease risk factors predict erectile dysfunction 25 years later: the Rancho Bernardo study. $J$ Am Coll Cardiol. 2004:43:1405-1411.

8. Ronald WL, Kersten S, Meyer F, et al. Epidemiology/risk factors of sexual dysfunction. J SexMed. 2004;1(1):35-39.

9. Mons P, Van Deyk K, Marquette K, De Bleser L, Budts W, De Geets S Sexual Functioning and congenital heart disease: Something to worry about? Int J Cardiol. 2007;121(1):30-35.

10. Montorsi P, Montorsi F, Schulman CC. Is erectile dysfunction the 'tip of the iceberg' of a systemic vascular disorder? EurUrol. 2003;44:352-354.

11. McGovern PG, Pancow JS, Shahar E, et al. Recent trends in acute coronary heart disease:mortality, morbidity, medical care and risk factors. N Engl J Med. 1996;334(14):884-890

12. Thompson IM, Tangen CM, Goodman PJ, Probstfield JL, Moinpour CM, Coltman CA. Erectile dysfunction and subsequent cardiovascular disease. JAMA. 2005;294:2996-3002.

13. Schouten BW, Bohnen AM, Bosch JL, et al. Erectile dysfunction prospectively associated with cardiovascular disease in the Dutch general population: results from the Krimpen study. Int J Impot Res. 2008;20:9299.

14. Ponholzer A, Temml C, Obermayr R, Wehrberger C, Madersbacher S. Is erectile dysfunction an indicator for increased risk of coronary heart disease and stroke? Eur Urol. 2005;48:512-518.

15. Feldman HA, Goldstein I, Hatzichristou DG,et al. Impotence and its medical and psychosocial correlates: results of the Massachusetts Male Aging Study. J Urol. 1999;151:54-61.

16. Virag R, Bouilly P, Frydman D. Is impotence an arterial disorder? A study of arterial risk factors in 440 impotent men. Lancet. 1985;1:181-184.

17. Martin-Morales A, Sanchez-Cruz JJ, Saenz de Tejada I, et al. Prevalence and independent risk factors for erectile dysfunction in Spain: results of the Epidemiologia de la Disfuncion Erectil Masculina Study. J Urol. 2001;166:569-575.

18. Blanker MH, Bohnen AM, Groeneveld FP, et al. Correlates for erectile and ejaculatory dysfunction in older Dutch men: a community based study. $J$ Am Geriatr Soc. 2001;49(4):436-442.

19. Solomon H, Man JW, Jackson G. Erectile dysfunction and the cardiovascular patient: endotelial dysfunction is the common denominator. Heart. 2003:89:251-253.

20. Mass R, Schwedhelem E, Albseier J, et al. The pathophysiology of erectile dysfunction related to endothelial dysfunction and mediators of vascular function. Vasc Med. 2002;7:213-225

21. Greenland P, LaBree L, Azen SP, et al. Coronary artery calcium score combined with Framingham score for risk prediction in asymptomatic individuals. JAMA. 2004;291:210-215.

22. Detrano RC, Doherty TM, Davies MJ, et al. Predicting coronary events with coronary calcium: pathophysiologic and clinical problems. Curr Probl Cardiol. 2000;25:374-402.

23. Schmermund A, Möhlenkamp S, Erbel R. Coronary artery calcium and its relationship to coronary artery disease. Cardio/ Clin. 2003;21(4):521ü534.

24. Selvin E, Burnett AL, Platz EA. Prevalence and risk factors for erectile dysfunction in the US. Am J Med. 2007;120(2):151-7.

25. Persu C, Cauni V, Gutue S, Albu ES, Jinga V, Geavlete P. Diagnosis and treatment of erectile dysfunction - a practical update. J Med Life. 2009;2(4):394-400

26. Aytac IA, Araujo AB, Johannes CB, Kleinman KP, McKinlay JB. Socioeconomic factors and incidence of erectile dysfunction: findings of the longitudinal Massachussetts male aging study. Soc Sci Med. 2000;51(5):771-778

27. Meller SM, Stilp E, Walker CN, Mena-Hurtado C. The link between vasculogenic erectile dysfunction, coronary artery disease, and peripheral artery disease: role of metabolic factors and endovascular therapy. $J$ Invasive Cardiol. 2013;25(6):313-319.

28. Greenstein A, Chen J, Miller H, Matzkin H, Villa Y, Braf Z. Does severity of ischemiccoronary disease correlate with erectile function? Int $\mathrm{J}$ Impot Res. 1997:9(3):123-126

29. Gupta BP, Clifton MM, Prokop L, Nehra A, Kopecky SL. The effect of lifestyle modification and cardiovascular risk factor reduction on erectile dysfunction: A systematic review and meta-analysis. Arch Intern Med. 2011;171(20):1797-1803.

30. Shamloul R, Ghanem H. Erectile dysfunction. Lancet. 2013;381(9861):153165.

31. Lue TF. Erectile dysfunction. New Engl J Med. 2000;342(24):1802-1813.

32. Billups KL, Bank AJ, Padma-Nathan $\mathrm{H}$, et al. Erectile dysfunction is a marker for cardiovascular disease: results of the minority health institute expert advisory panel. J Sex Med. 2005;2:40-50. 
33. Lakka HM, Laaksonen DE, Lakka TA, et al. The metabolic syndrome and total and cardiovascular disease mortality in middle-aged men. JAMA. 2002:288:2709-2716

34. Van Gaal LF, Rissanen AM, Scheen AJ, et al. Effects of the cannabinoid-1 receptor blocker rimonabant on weight reduction and cardiovascular risk factors in overweight patients: 1-year experience from the RIO-Europe study. Lancet. 2005;365:1389-1397.

35. Selvin E, Burnett AL, Platz EA. Prevalence and risk factors for erectile dysfunction in the US. Am J Med. 2007;120(2):151-157.

36. Kubin M, Wagner G, Fugl-Meyer AR. Epidemiology of erectile dysfunction. Int J Impot Res. 2003;15(1):63-71.

37. Akdemir R, Karakurt O, Orcan $\mathrm{S}$, et al. Comparison between primary angioplasty and thrombolytic therapy on erectile dysfunction after acute ST elevation myocardial infarction. Asian J Androl. 2012;14(5):784-787.

38. Montorsi P, Ravagnani PM, Galli S, et al. Association between erectile dysfunction and coronary artery disease: matching the right target with the right test in the right patient. Eur Urol. 2006;50:721-731.

39. Montorsi F, Briganti A, Salonia A, et al. Erectile dysfunction prevalence time of onset and association with risk factors in 300 consecutive patients with acute chest pain and angiographically documented coronary artery disease. Eur Urol. 2003;44(3):360-364; discussion 364-365.

40. Hodges LD, Kirby M, Solanki J, O'Donnell J, Brodie DA. The temporal relationship between erectile dysfunction and cardiovascular disease. Int J Clin Pract. 2007;61(12):2019-2025.

41. Gazzaruso C, Giordanetti S, De Amici E. Relationship between erectile dysfunction and silent myocardial ischemia in apparently uncomplicated type 2 diabetic patients. Circulation. 2004;110(1):22-26.
42. Solomon H, Man JW, Wierzbicki AS, Jackson G. Relation of erectile dysfunction to angiographic coronary artery disease. Am J Cardiol. 2003:91(2):230-231.

43. Vlachopoulos C, Rokkas K, loakeimidis N. Prevalence of asymptomatic coronary artery disease in men with vasculogenic erectile dysfunction: a prospective angiographic study. Eur Urol. 2005;48(6):996-1003.

44. Montorsi P, Ravagnani PM, Galli S. Association between erectile dysfunction and coronary artery disease: role of coronary clinical presentation and extent of coronary vessels involvement: the COBRA trial. Eur Heart J. 2006;27(22):2632-2639.

45. Araujo AB, Travison TG, Ganz P. Erectile dysfunction and mortality. J Sex Med. 2009;6(9):2445-2454.

46. Inman BA, Sauver JL, Jacobson DJ. A population-based, Iongitudinal study of erectile dysfunction and future coronary artery disease. Mayo Clin Proc. 2009;84(2):108-113

47. Chew KK, Finn J, Stuckey B. Erectile dysfunction as a predictor for subsequent atherosclerotic cardiovascular events: findings from a linkeddata study. J Sex Med. 2010;7(1):192-202.

48. Hall SA, Shackelton R, Rosen RC, Araujo AB. Sexual activity, erectile dysfunction, and incident cardiovascular events. Am J Cardiol. 2010;105(2):192-197

49. Polonsky TS, Taillon LA, Sheth $\mathrm{H}$, et al. The association between erectile dysfunction and peripheral arterial disease as determined by screening ankle-brachial index testing. Atherosclerosis. 2009;207(2):440-444.

50. Nehra A, Jackson G, Miner M, et al. The Princeton III Consensus recommendations for the management of erectile dysfunction and cardiovascular disease. Mayo Clin Proc. 2012;87(8):766-78. 